\title{
General Anxiety Disorder-Related Coronavirus Disease-19 Outbreak in Indonesia: A Case Report
}

\author{
Patricia Wulandari ${ }^{1 *}$, Rachmat Hidayat $^{2}$ \\ ${ }^{1}$ Cattleya Mental Health Center, Palembang, Indonesia; ${ }^{2}$ Department of Biology, Faculty of Medicine, Universitas Sriwijaya, \\ Palembang, Indonesia
}

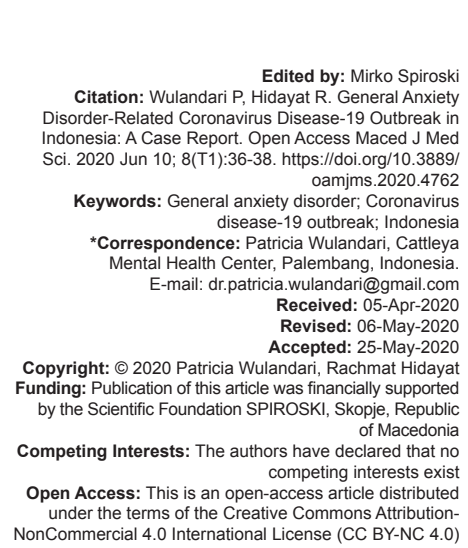

\section{Background}

Since December 2019, the world was shocked by a new outbreak caused by severe acute respiratory syndrome coronavirus 2 (SARS-CoV2) or better known as coronavirus disease-19 (COVID-19). This virus is feared due to the symptoms that are quite heavy on immunocompromised individuals and very massive spread [1], [2]. The prevention efforts in the form of social distancing, maintaining cleanliness of the body and hands repeatedly, and government-supported policies in the form of "stay at home, work from home, and school from home," make very significant changes in all areas of human life. People who are accustomed to directly socializing (physically) become distant for fear of spreading the virus through physical contact. This turned out to cause a stressful situation for some people, especially people who had previously experienced anxiety disorders. We report cases of general anxiety disorder-related to the COVID-19 outbreak in Indonesia.

\section{Case Presentation}

Miss A, a 23-year-old female, $1^{\text {st }}$ in birth order, a dentistry student living in a boarding house in East Java, Indonesia, along with her friend and coming from a middle-up income family background, came to psychiatric consultation with complaints of difficulty of breathing for 1 month ago. The patient claimed to experience anxiety so severe that she was unable to move as usual. This anxiety began to get worsen, especially since the SARS CoV-2 (COVID 19) outbreak appeared in Indonesia. In addition, she also recently experienced a failure in her final examination so that her study period as a dentistry student must be extended. Exploration of history revealed that the patient initially experience a feeling of heaviness in the chest, difficulty breathing, palpitation, and sometimes feeling sad due to her failure before. All of these complaints were felt by the patient, especially when they heard that there was a COVID 19 patient who died or there were new patients who were confirmed to be positive. Examination of the cardiovascular and respiratory system shows that 
the organ is functioning properly, and there are no abnormalities.

Due to the disturbance experienced by the patient, she was unable to do daily activities. The government's call for citizens to remain at home during the outbreak makes patients more stressed because she cannot go home to meet their parents.

On further psychiatric examination, there were afraid of death preoccupation, fears of contracting SARS-CoV2 (COVID-19), and preoccupation with thoughts that disappointed her parents. At this time, she also began to experience symptoms of depression in the form of pervasive sadness, feelings of anhedonia, despair, and low self-esteem and felt himself useless and disappointing. There is no history of suicidal ideation, delusions, or hallucinations. There is no specific fear of a particular object.

Family history shows a dysfunctional family, where her father is authoritarian, while the mother treats the patient permissively. She also said and she had seen her father threatening her mother abusively and often angry excessively in front of her children. However, no history of physical trauma or sexual abuse was found during development.

On the mental status examination, the patient was alert and oriented, with a preoccupation with the fear of contracted an illness and was afraid of disappointing his parents. There are symptoms of moderate depression that accompany patient complaints. Insight was preserved, for example, she was sure that her fear was irrational, illogical, and caused by psychological disorders, and the patient agreed to be treated. A diagnosis of general anxiety disorder was considered. She was started on fluoxetine $20 \mathrm{mg} /$ day and clobazam $5 \mathrm{mg} /$ day. Personality assessment using Millon Clinical Multiaxial Inventory IV shows that the dominant patient's personality is narcissistic, histrionic, and turbulent type, which is accompanied by clinical depression, anxiety, tension, insomnia, and fatigue that have no apparent cause. The graphic test with a house tree person shows that the patient experienced extreme anxiety and had past psychological trauma. The degree of patient anxiety measured by the Hamilton Anxiety Rating Scale (HARS) is 26 (severe anxiety).

Patients agreed to undergo psychotherapy in the form of cognitive-behavioral therapy through teleconference plus a gradual exercise of muscle progression relaxation. Patients are asked to identify situations that make patients anxious and give a rating on what situations; most patients feel anxious. Patients are also asked to keep a daily journal, and notes in the journal will be discussed with the psychiatrist. Patients are also asked to reduce exposure to news about COVID-19 and reduce the intensity of using social media such as Instagram, WhatsApp, and others.

After six sessions of psychotherapy online and progressive muscular relaxation exercises, the patient's anxiety begins to decrease (HARS 13). Patients began to like a new hobby in the form of aerobic exercise as a substitute for their internet browsing habits and social media. The patient claimed to be more passionate about living life and ready to complete her education as a dentist.

\section{Discussion}

The SARS-COV2 or COVID-19 pandemic is increasing the attention of specialists around the world, including psychiatrists. In this pandemic outbreak, it is estimated that there will be an increase in mental health disorders during and after the pandemic.

Individuals who previously have personality disorders or psychiatric disorders will be prone to experience exacerbations or worsening in symptoms during a pandemic. Studies show generalized anxiety disorder that may be caused by genetic and nongenetic factors. This non-genetic factor, in the form of stressful events faced by patients, is thought to trigger anxiety symptoms in patients. Several neurotransmitter systems, including norepinephrine, GABAergic, and the serotonergic system in the frontal lobe and limbic system, are thought to play a role in mediating this disorder [3], [4].

The main psychological burdens such as anxiety [5], generalized anxiety disorder, and panic attack can worsen shortness of breath; aggressive behavior which results in patient disobedience and anxiety of medical personnel and obsessive behavior that can cause people, including medical personnel dysfunction, depression, and sleep disorders which are common psychological reactions. Coronaphobia, a new term in the psychiatry literature referring to excessive fear of being infected by SARS-COV2 or COVID 19 [6]. Being Infected by influenza, having close relatives or friends with this fatal virus, and strong fear of infection have been reported as important predictors of stress posttrauma [7], [8].

In this case, a pharmacological intervention was carried out in the form of a selective serotonin reuptake inhibitor agent, fluoxetine, and benzodiazepines (clobazam) to reduce the somatic symptoms experienced by the patient. After the anxiety symptoms decrease, psychotherapy intervention in the form of cognitive behavior therapy and online progressive muscular relaxation training assistance was started, and continued to give transfer of stimulus in the form of reducing exposure to COVID 19 news on electronic media and social media. And given the transfer of stimulus in the form of reducing exposure to COVID-19 news on electronic media and social media. This has been proven to reduce symptoms of anxiety and depression gradually in patients. This is in line with 
a review of published research that has shown that telepsychiatry is an efficient intervention in emergency settings [8], [9], [10], [11]. However, obstacles such as the use of the internet and adequate collaboration must be overcome [12], [13], [14]. In a situation like the current coronavirus pandemic which prohibits people from gathering, this is a very important issue in preventing COVID-19 spreading.

\section{Conclusion}

General anxiety disorder, especially due to the COVID-19 outbreak, should be managed appropriately and comprehensively. The pandemic situation and widespread spread of the disease cause psychotherapy to be modified in such a way that assistance can be carried out online.

\section{References}

1. Wang C, Horby PW, Hayden FG, Gao GF. A novel coronavirus outbreak of global health concern. Lancet. 2020;395(10223):4703. https://doi.org/10.1016/s0140-6736(20)30185-9. PMid:31986257

2. Zarghami M. Psychiatric aspects of coronavirus (2019-nCoV) infection. Iran J Psychiatry Behav Sci. 2020;14(1):e102957. https://doi.org/10.5812/ijpbs.102957

3. Yoo JH. The fight against the 2019-nCoV outbreak: An arduous march has just begun. J Korean Med Sci. 2020;35(4):e56. https://doi.org/10.3346/jkms.2020.35.e56 PMid:31997618

4. Stroebe M, Schut H, Boerner K. Cautioning health-care professionals. Omega (Westport). 2017;74(4):455-73. https:// doi.org/10.1177/0030222817691870
PMid:28355991

5. Doka KJ. Grief is a Journey: Finding Your Path Through Loss. New York: Atria Books; 2016. p. 108-16.

6. Angus Reid Institute. Half of Canadians Taking Extra Precautions as Coronavirus Continues to Spread Around the Globe. Available from: http://www.angusreid.org/Wp-content/ uploads/2020/02/2020.02.04_Coronavirus.pdf. [Last accessed on 2020 Feb 06].

7. Asmundson GJ, Taylor S. Coronaphobia: Fear and the 2019nCoV outbreak. J Anxiety Disord. 2020;70:102196. https://doi. org/10.1016/j.janxdis.2020.102196

PMid:32078967

8. Fisher D, Heymann D. Q\&A: The novel coronavirus outbreak causing COVID-19. BMC Med. 2020;18(1):57. https://doi. org/10.1186/s12916-020-01533-w

PMid:32106852

9. Wu JT, Leung K, Leung GM. Nowcasting and forecasting the potential domestic and international spread of the 2019-nCoV outbreak originating in Wuhan, China: A modelling study. Lancet. 2020;395(10225):689-97. https://doi.org/10.1016/ s0140-6736(20)30260-9

10. Huang Y, Zhao N. Generalized anxiety disorder, depressive symptoms and sleep quality during COVID-19 epidemic in China: A web-based cross-sectional survey. Med Rxiv Preprint. 2020;23(2):15-9. https://doi.org/10.21203/rs.3.rs-17172/v1

11. Sun L, Sun Z, Wu L, Zhu Z, Zhang F, Shang Z, et al. Prevalence and risk factors of acute posttraumatic stress symptoms during the COVID-19 outbreak in Wuhan, China. Med Rxiv Preprint. 2020; 23(2):11-5. https://doi.org/10.1101/2020.03.06.20032425

12. Zhang W, Zhao X, Wu W, Zhang J. Recommended psychological crisis intervention response to the 2019 novel coronavirus pneumonia outbreak in China: A model of West China Hospital. Precis Clin Med. 2020;24(2):10-5. https://doi.org/10.1093/ pcmedi/pbaa006

13. Hilty DM, Ferrer DC, Parish MB, Johnston B, Callahan EJ, Yellowlees PM. The effectiveness of telemental health: A 2013 review. Telemed J E Health. 2013;19(6):444-54. https://doi. org/10.1037/e574782013-009 PMid:23697504

14. Duan L, Zhu G. Psychological interventions for people affected by the COVID-19 epidemic. Lancet Psychiatry. 2020;7(4):300-2. https://doi.org/10.1016/s2215-0366(20)30073-0 PMid:32085840 